\title{
Warehouse Management System with Customer Analysis for RichB Trading
}

\author{
Rossette Joyce G. Ramirez ${ }^{1+}$, Angelica M. Bustamante ${ }^{1}$, Kim Hanna P. Llamera ${ }^{1}$, Bernadette N. \\ Reyes ${ }^{1}$, and John Benedic R. Enriquez ${ }^{1}$ \\ ${ }^{1}$ Far Eastern University - Institute of Technology, Philippines
}

\begin{abstract}
The Research was about the warehouse management system is made to be more efficient to both business and their customers. It helps the business to manage the sales, inventory, deliveries, and orders that are happening inside and outside of the warehouse. The system has two parts; online ordering and main system or the warehouse management system itself. Through online ordering, it is easier for both customers and sales agents to take orders or purchase products. In the main system, there is SMS where the system sends a confirmation message to the customers and they can reply to that message. As for analytics, the system has Sales Analytics where daily, weekly, monthly and yearly sales generated, Customer Analysis to improve the relationship between customers and business, Market Basket Analysis to determine what items are frequently bought together, Sentiment Analysis to identify and categorize the comments of the customers and Forecasting Analysis to predict the 5 years' sales per product category.
\end{abstract}

Keywords: sentiment, analytics, management system, forecasting.

\section{Introduction}

Information Technology and Information System are observed as two of the most used and needed tools when it comes to business and has been innovated as time goes by. Information System is defined as a set of coordinated network components that act together to produce, distribute and process information while Information Technology is used for storing, retrieving, manipulating of data. The Warehouse Management System with Customer Analysis for RichB Trading to help the business in managing the sales, inventory, deliveries and other operations that are happening inside and out of the warehouse. This proposed system used a cloud-based infrastructure for fast and real time connection. Through cloud-based warehouse management system, users can now be able to access the system through smartphones.

On the other hand, customer analysis is the type of business analytics that improves the relationship between the customer and the business and also to satisfy the customers and standing. The Market Basket Analysis is a type of business analytics that identifies the products that the customers always order. This type of analytics can help the warehouse to identify the most purchased products and at the same time, it would be easier for the business to decide what products should the warehouse needs to purchase from the suppliers. The Sentiment Analysis is used to know if the customers have any recommendation or concerns about the performance of the warehouse. Sales Analysis Report is a kind of business analytics where the business can monitor the warehouse sales if there is an increase or decrease in the production.

RichB Trading is one of the warehouses that distributed different products from small to large stores including canteens of different schools all over the Bataan area. Due to the increasing number of competition in the industry, RichB Trading should come up with a better system and marketing strategy so that it can outweigh the competitors.

\footnotetext{
+ Corresponding author. 09988633495

E-mail address: johnbenedic.enriquez@gmail.com
} 


\section{Methodology}

\subsection{Research objectives}

The development of Warehouse Management System with Customer Analysis with features: Management Modules, Reports, Ordering Module, Business analytics using data mining and text mining (Customer Analysis, Market Basket Analysis and Sentiment Analysis), and centralized database for securing records and monitoring of stocks or products.

\subsection{Related studies and literatures}

Assessing the customer's nature of purchasing of products, quality of service of the sales agents and customer services [1] in finding the specific products and services that can be offered to the customer [3]. To assign identifiers for every product to identify right away the different products in the warehouse [4]

Having a module that will monitory the customer's orders to reduce errors [5]. In applying the sentiment analysis, it has been used by different organizations to know the customers wants and needs. [6]. A similar to study about sentiment analysis was [7] says that it could recognize the positive and negative comments that the customer will be giving. With the amount of data needed for sentiments analysis, the collected recommendation or information with the use of twitter that can help the business and come up with a better marketing strategies and also give the customers a good and quality service [8].

To have an ease of access to the system, using a cloud-based system would be advisable for monitoring and accessing the system in real time [9]. For securing the safety and storage of the systems database, stocks and products in the inventory a level of hierarchy. It was also effective to have a system that will translate and monitor the daily operations or the day-to-day operations of warehouse by getting enough data from the upper-level host of the WMS [10].

Business analyst should be able to grasp and understand the business community in learning how to adopt and evolve with the processes, products and emerging technologies that are happening inside the core of the business [2]. To achieve a successful relationship with a customer, by having wide range of customer's preferences, business transactions and to gain more profit as the proposed system will also engage with the customer analytics. In identifying the products with the most number of sales, Market basket analysis is used to identify products that can be similar with the most number of transactions, to come up with a better marketing strategies.

\subsection{Project design}

$\begin{array}{ll}\text { Input Process } & \text { Output }\end{array}$

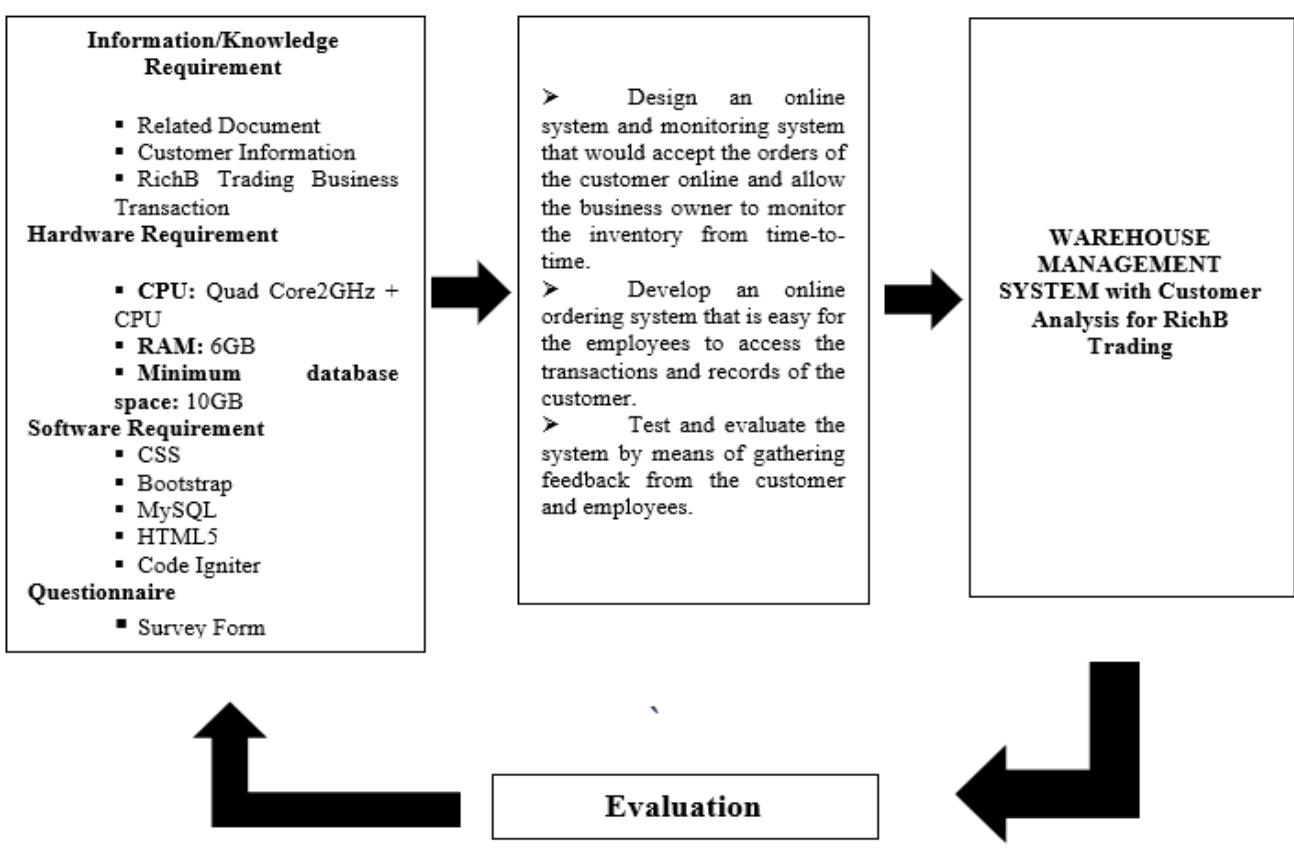

Fig. 1: Conceptual Framework 


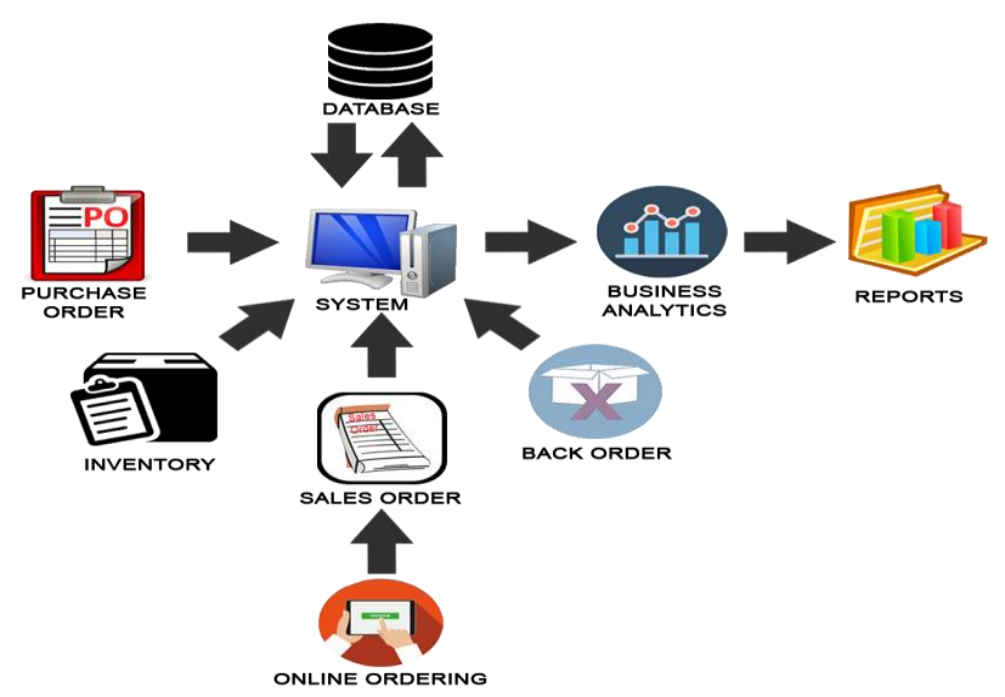

Fig. 2: System Architecture

The figure 2 shows the structure of the proposed system, the system will have modules like Purchase Orders, Sales Orders, Inventory Management, Back Orders, and Online Ordering. With the feature of reporting under the business analytics feature.

\subsection{Project development}

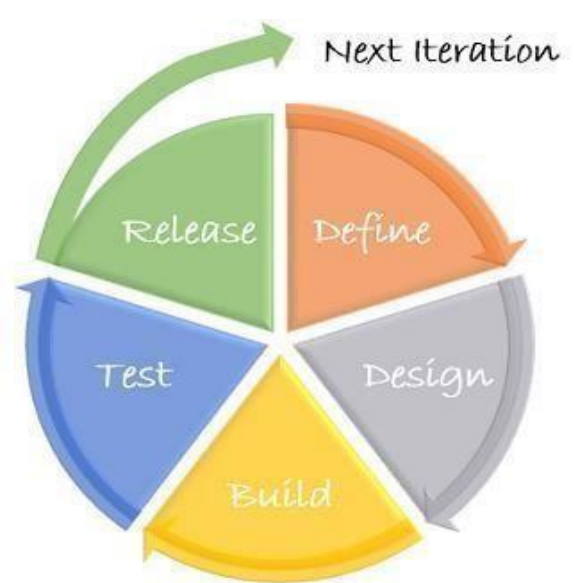

Fig. 3: Agile Methodology Process

Agile methodology has transformed information technology in helping to be successful in software development. There are four values in Agile Methods according to the Agile Manifesto these includes, individuals and interaction, working software, customer collaboration, and response to change. Agile Method is focused more on development rather than documentation, which is a good thing because the focus is on the development process.

The sampling technique that has been used in this study is the purposive sampling technique. The researchers believe that it was the technique that was suitable for the system since the users are only the owner, sub-administrator, and the customer of the warehouse.

$$
\bar{x}=\frac{\sum_{i=1}^{n}\left(x_{i} * w_{i}\right)}{\sum_{\substack{i=1 \\ n}}^{n} w_{i}}
$$


Table 1: Likert Scale

\begin{tabular}{|c|c|c|}
\hline SCALE & RANGE & INTERPRETATION \\
\hline 5 & $4.51-5.00$ & Excellent \\
\hline 4 & $3.51-4.50$ & Very Good \\
\hline 3 & $2.51-3.50$ & Good \\
\hline 2 & $1.51-2.50$ & Fair \\
\hline 1 & $1.00-1.50$ & Poor \\
\hline
\end{tabular}

Table 2 shows the transmutations of the Likert scale that will be used in determining the feedbacks of the customers and the office employees who will evaluate the overall functionality of the developed system.

\section{Results}

The survey was conducted with 20 participants; employees and customers from RichB Trading. Through this representative sample population surveys were given out to find the main evaluation results of the created system. The obtained results were treated with statistical analysis and are presented in this part of the chapter. To better understand and comprehend the garnered results, discussions below will furthermore show and elaborate the said contents.

Table 2. Summary of Respondents Assessment on the Proposed System

\begin{tabular}{|c|c|c|c|c|c|c|}
\hline & \multicolumn{2}{|c|}{ CUSTOMER } & \multicolumn{2}{|c|}{ EMPLOYEE } & \multicolumn{2}{|c|}{$\begin{array}{l}\text { GENERAL } \\
\text { AVERAGE }\end{array}$} \\
\hline AREA & $\overline{\mathrm{x}}$ & 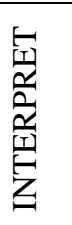 & $\overline{\bar{x}}$ & 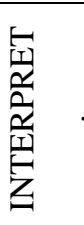 & $\overline{\bar{x}}$ & 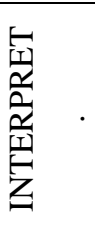 \\
\hline 1.Functionality & 4.62 & $\bar{E}$ & 4.55 & $\mathrm{E}$ & 4.59 & $\mathrm{E}$ \\
\hline 2.Usability & 4.71 & $\mathrm{E}$ & 4.65 & $\mathrm{E}$ & 4.68 & $\mathrm{E}$ \\
\hline 3.Reliability & 4.50 & $\mathrm{VG}$ & 4.67 & $\mathrm{E}$ & 4.59 & $\mathrm{E}$ \\
\hline 4. Performance & 4.58 & $\mathrm{E}$ & 4.50 & $\mathrm{VG}$ & 4.54 & $\mathrm{E}$ \\
\hline 5.Security & 4.68 & $\mathrm{E}$ & 4.67 & $\mathrm{E}$ & 4.68 & $\mathrm{E}$ \\
\hline $\begin{array}{l}\text { Composite } \\
\text { Mean }\end{array}$ & 4.62 & $\mathrm{E}$ & 4.61 & $\mathrm{E}$ & 4.62 & $\mathrm{E}$ \\
\hline
\end{tabular}

LEGEND: Excellent (E) - 4.51-5.00, Very Good (VG) - 3.51-4.50, Good (G) - 2.51-3.50, Fair (F) - 1.51-2.50, Poor (P) $-1.00-1.50$

Table 3 shows the summary of respondents' assessment on the proposed system. Reflected are the rate of the customers and employees on the functionality, usability, reliability, performance, and security. Among the area stated, both Usability and the Security of the system got the highest rate of 4.68. This proves that the security and the usability of the system are really effective. Both functionality and the reliability got the second highest rate of 4.59. The employees' performance was given the lowest rating among all areas. This shows that the proponents need to focus on improving the performance of the system for both the customers and employees of the warehouse.

\section{Reflections / Conclusions}

After gathering enough information through survey, the researchers were able to conclude the following:

\subsection{Develop a warehouse management system.}

The researchers were able to create a Warehouse Management System with modules for Inventory, Customer, Sales Order, Purchase Order, Back Order, and Delivery. These modules contain the accurate 
reports, products available, in critical level, out of stocks, products that have been returned because of defects and expiration and customer payment information. In the performed survey, the functionality got the second highest rate which can be considered to be accomplished by the researchers but at the same time still needed a little improvement.

\subsection{Create a database wherein it is used to save all incoming information from the client and their customer.}

The developers are able to create a database that fits the requirements needed for the business and its process. Through the relationship of the entities of the business, the system was developed. In the survey, it shows that some of the data also needed a little improvement especially in generating high and low sales of the product.

\subsection{Create reports for the daily, weekly, monthly, and yearly report sales of the warehouse.}

A report is a great tool to ensure and keep track of your sales and customers' behavior by their transactions and information. Different analytics are used in producing an accurate presentation of the sales forecast (daily, weekly, monthly and yearly). In the survey, it shows that the daily, weekly, monthly and yearly report still needed improvement. Also, the sales forecast was able to determine the daily, weekly, monthly and yearly report using moving average.

\subsection{Notification for the below the minimum number of stocks and products that are closed to its expiration date.}

The developers were able to give the warehouse a notification for the minimum number of stocks and products that are closed to its expiration date. The critical level in the inventory module serves as the indicator for the warehouse to request for a supply of product needed. Also, notification for the expiration date of a product indicates that the product will nearly be expired. The critical level and out of stock product is represented by red for out of stock and orange for the critical level.

After all the investigation, the researchers concluded that the system was acceptable since both customers and employees of the warehouse rated the system through survey and garnered good and excellent results.

\section{Acknowledgements}

Mr. \& Mrs. Ramirez, Mr. \& Mrs. Bustamante, Mr. \& Mrs. Llamera, Mr. \& Mrs. Reyes, Mr. \& Mrs. Enriquez, Municipal of Macalelon - Quezon, Quezelco1, Friends and Colleagues.

\section{References}

[1] Anna Margarita M. Agulo, K. M. (2015). Customer Satisfaction on the Quality Services of one Department Store in Batangas City, Philippines. Asia Pacific Journal of Academic Research in Business Administration, Vol. 1 No. 1.

[2] BLAIS, S. P. (2012). Business Analysis Best Practices for Success. Canada: John Wiley \& Sons, Inc., Hoboken, New Jersey.

[3] Cohan Sujay Carlos, M. Y. (2012, December). Intention Analysis for Sales, Marketing and Customer Service. Retrieved from http://www.aclweb.org: http://www.aclweb.org/anthology/C12-3005

[4] Duan, L. (2012). Iowa Research Online. Retrieved from ir.uiowa.edu: https://ir.uiowa.edu/cgi/viewcontent.cgi?article=3289\&context=etd

[5] Fernandez, D. J. (2012, June). EL GRANDE FASHION HOUSE ONLINE ORDERING SYSTEM. Retrieved from http://elgrandefashionhouse.atwebpages.com/Chapter\%201.pdf

[6] Kurt Junshean Espinosa, K. L. (2016, December 11). Sentiment analysis of Facebook statuses using Naive Bayes classifier for language learning. Retrieved from https://pdfs.semanticscholar.org/8a1f/a9ceee8332f35c118504f237c536cd500112.pdf

[7] Muhammad Zubair Asghar, A. K. (2017, February 27). Lexicon-enhanced sentiment analysis framework using rule-based classification scheme. 
[8] Nathaniel Ocoa, L. R. (2016, October 30). Resources for Philippine Languages: Collection, Annotation, and Modeling. Retrieved from http://www.aclweb.org/anthology/Y16-3015

[9] Peter, T. Y. (n.d.). Complete warehousing functionality with Magaya Warehouse Management System. Retrieved from http://www.magaya.com/solutions/warehouse-management-system

[10] Ramaa.A, K. T. (2012). Impact of Warehouse Management System in a Supply Chain. 